\title{
Possibilities of the exposure reduction of hands during the preparation and application of radiopharmaceuticals
}

\author{
Hudzietzova $\mathrm{J}^{1}$, Fulop $\mathrm{M}^{2}$, Sabol $\mathrm{J}^{3}$ \\ Czech Technical University in Prague, Faculty of Biomedical Engineering - Department of Health Care \\ Disciplines and Population Protection, Kladno, Czech Republic. hudzietzova@gmail.com
}

\begin{abstract}
BACKGROUND: The current routinely used methods of estimating the skin equivalent dose relies on the finger dosimetry which usually largely underestimates the real maximum exposure and thus appropriate correction factors have to be used.

METHODS: The group under the investigation consisted of 10 workers preparing and 5 workers administering radiopharmaceuticals labelled with ${ }^{18} \mathrm{~F}$. The monitoring was carried out using 12 pairs of thermoluminiscent dosimeters (TLDs) placed on each hand of the worker. A total of 46 measurements were completed. The maximum exposure of the skin of hands, defined in terms of the quantity of the personal dose equivalent $H_{0}(0.07)$, was related to the unit activity of radiopharmaceutical with which the worker came into the contact during the measurement.

RESULTS: The exposure of the hands of workers handling ${ }^{18} \mathrm{~F}$-labelled radiopharmaceuticals showed significant inhomogeneity. Out of 15 workers, in $53 \%$ of cases, the maximum skin exposure was observed on the tip of their index finger. It was estimated that in about $60 \%$ of the cases (during the preparation and administration of radiopharmaceuticals), the exposure may exceed the 3/10 of the annual dose limit. Moreover, in $40 \%$ of all cases, the exposure may even be higher than this dose limit. The established relevant correction factors reached the values up to 8 (as for preparations) and 13 (as for administrations).

CONCLUSIONS: The study resulted in the establishment of the appropriate correction factors and in the recommendations of procedures aimed at the further reduction of the exposure of extremities (Tab. 3, Fig. 2, Ref. 17). Text in PDF www.elis.sk.
\end{abstract}

KEY WORDS: ${ }^{18} \mathrm{~F}$, nuclear medicine, radiation protection, skin exposure of hands, exposure optimization.

\section{Introduction}

The radiation burden of workers at PET and PET/CT departments is associated with the preparations of radiopharmaceuticals (filling syringes with radioactive material), administration of radiopharmaceuticals to patients, other contacts with patients following the application, and, in principle, also with the production of radiopharmaceuticals using a cyclotron (if the accelerator is installed in the department). In some specific operations, related to the preparation and application of radiopharmaceuticals, such

${ }^{1}$ Czech Technical University in Prague, Faculty of Biomedical Engineering - Department of Health Care Disciplines and Population Protection, Kladno, Czech Republic, ${ }^{2}$ Slovak Medical University, Bratislava, Faculty of Public Health, Radiation Protection Centre, Bratislava, Slovakia, and ${ }^{3}$ PACR, Faculty of Safety Management, Department of Crisis Management, Prague, Czech Republic

Address for correspondence: J. Hudzietzová, MD, Czech Technical University in Prague, Faculty of Biomedical Engineering - Department of Health Care Disciplines and Population Protection, Nam. Sitna 3105, CZ27201 Kladno, Czech Republic Phone: +420.732732200

Acknowledgements: Thanks to all the staff of PET department of the Na Homolce Hospital, who assisted us during the measurements. Without their cooperation it would not be possible to complete the work. The paper was partially funded under the project SGS15/114/OHK4/1T/17. work may potentially significantly contribute to the exposure of the hands. This is broadly in line with findings of the well-known studies carried out under the project ORAMED (Optimization of Radiation Protection of Medical Staff) $(1,2)$, where it was estimated that every fifth nuclear medicine worker may exceed the dose limit for the skin which is $500 \mathrm{mSv} / \mathrm{y}$ (3) set by the international standards. There were also some other studies which documented that the annual skin dose of hands may not only exceed the reference level (150 mSv/year) but in a number of cases also the relevant dose limit (4-8).

Based on the results of measurements under the project ORAMED (124 workers monitored at 32 nuclear medicine departments in 7 European countries), several recommendations aimed at reducing exposure of the hands have been proposed $(1,9)$ :

- The monitoring of radiation exposure in radiation workers by means of finger dosimeters is essential for the assessment of the exposure of extremities;

- The positioning of the dosimeter for routine monitoring of staff should be decided taking into account the results of preliminary measurements of representative workers (if this is not possible, the preferable position of the dosimeter is at the root of the index finger on the non-dominant hand of workers with the sensitive side of the dosimeter facing the palm); 
413-417

- To estimate the maximum skin equivalent dose, the reading of the ring dosimeter positioned at the root of index finger of nondominant hand, the correction factor of 6 should be applied;

- Shielding vials and syringes with a radiopharmaceutical are essential, however, this itself does not guarantee low exposure of hands because sometimes shielding is not properly used;

- The minimum acceptable thickness of shielding of a syringe is $5 \mathrm{~mm}$ of tungsten while for vial shielding, the minimum thickness should be $3 \mathrm{~cm}$ of lead equivalent;

- Any tools lengthening the distance between the source (radiopharmaceutical) and hands (fingers) always significantly reduce the exposure;

- Although the experience of the staff is important, even more important seems to be an adequately trained worker in applying good working practices in line with the latest recommendations for specific operations;

- The individual operations should be carried out carefully without undue hurry paying special attention to the application of efficient use of suitable shielding and also using working tools such as tweezers $(5 \mathrm{~cm}$ long tweezers can reduce the exposure by a factor of 6 ).

The purpose of this paper is to assess the radiation dose to workers' hands and to consider possible options for reducing this exposure during the preparation and application of radiopharmaceuticals labeled with ${ }^{18} \mathrm{~F}$.

\section{Material and methods}

The group under the study consisted of workers preparing (filing a syringe with radiopharmaceuticals) and applying radiopharmaceuticals labeled with ${ }^{18} \mathrm{~F}$. Measuring one worker (25 preparations and 25 applications) accounted for several days wearing gloves with TLDs during these operations. The measurement time per worker (1-4 days) depended on the operation (preparation or application) and the number of patients examined. A total of 15 workers were monitored (10 workers preparing and 5 workers administering radiopharmaceuticals), each wor-

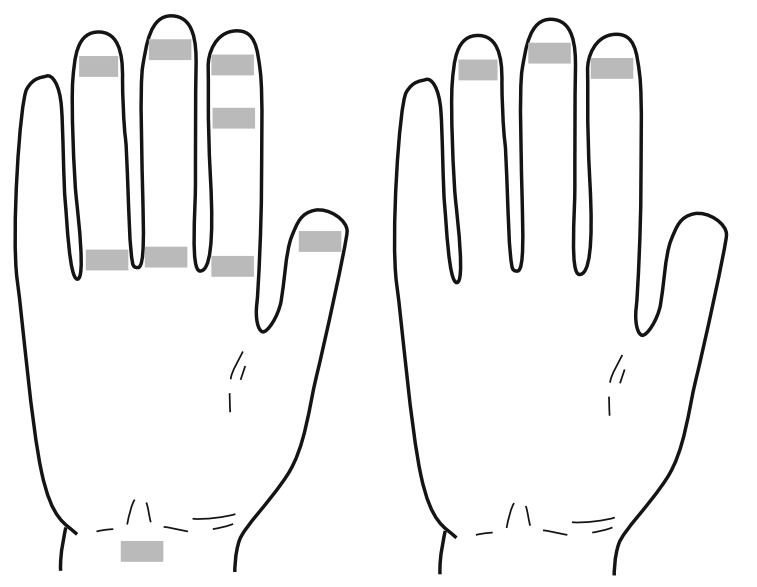

Fig. 1. The locations of TLDs (left - the palm of his right hand, right - the opposite side of the left hand).

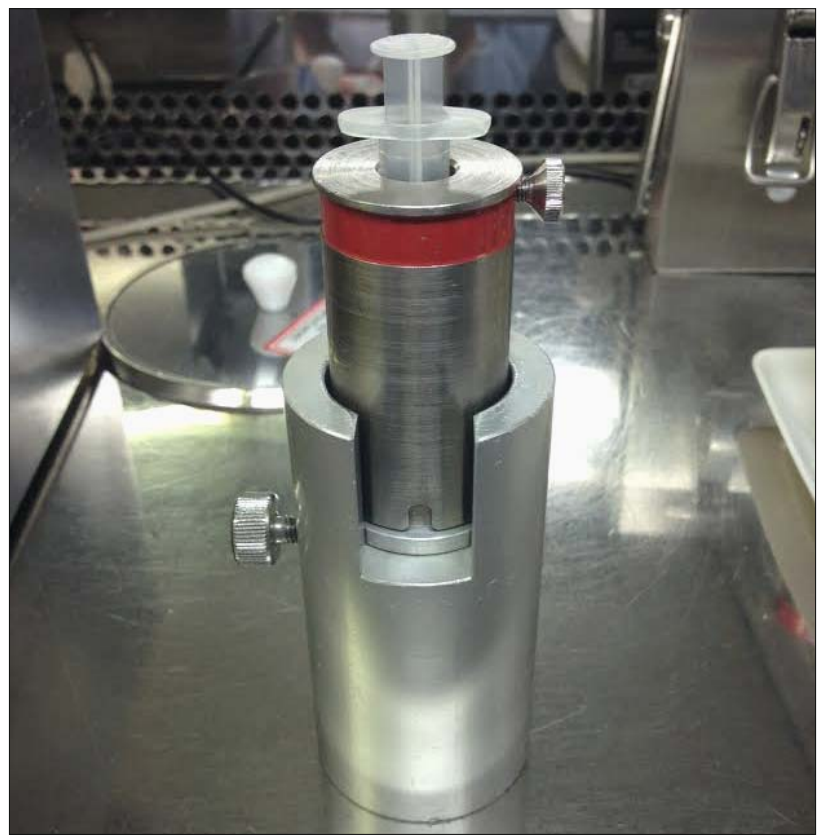

Fig. 2. Aluminum stand with a syringe in the tungsten shielding.

ker was measured three times with the exception of one worker who was measured four times due to the significantly higher exposure compared to other workers handling the same activity). To determine the personal dose equivalent $\mathrm{H}_{\mathrm{p}}(0,07)$, thin TLDs with thickness of $8.5 \mathrm{mg} / \mathrm{cm}^{2}$ (MCP-Ns) and TLDs with that of 225 $\mathrm{mg} / \mathrm{cm}^{2}$ (MCP-7) (10) were used. The dosimeters were calibrated using a finger phantom and a ${ }^{137} \mathrm{Cs}$ source in accordance with the procedures prescribed by ISO 4037 . The overall uncertainties of the results consisted of the calibration uncertainty, uncertainty of reading the TLDs as well as uncertainty caused by the inhomogeneous radiation field. For these reasons, the accuracy and reproducibility of the TLD positioning on hands was also very important.

The TLDs were placed at 12 positions on each operator's hands (Fig. 1). All results of $\mathrm{H}_{\mathrm{p}}(0.07)$ corresponding to individual positions were normalized to the activity of $1 \mathrm{GBq}$. For all workers identical protocols were kept to ensure subsequent comparison and evaluation. In addition, during the measurements also photos and videos were taken in order to reflect the procedures during the work of individual persons monitored.

In general, workers preparing and applying radiopharmaceuticals at individual PET departments differed as to their workflow and technological equipment.

\section{Preparation of the radiopharmaceutical}

The personnel preparing radiopharmaceuticals for individual patients used a semiautomatic dispensing station situated in a laminar box. The station automatically filled syringes with required amount of radiopharmaceuticals. The manufacturer has advised to fix the needle by means of several tools (e.g., an aluminum stand for the needle that had no shielding effect, but served for connecting the needle without operator's fingertips being near the syringe cone during the manipulation) (Fig. 2). The radiopharmaceutical, 
prepared for each patient using these procedures, was subsequently moved in the shield to the application room.

\section{Application of a radiopharmaceutical}

This has been carried out using two different techniques:

- A physician applied the radiopharmaceutical using a syringe in the tungsten shielding by means of a cannula; and

- The radiopharmaceutical in tungsten shielding was applied without using the cannula.

To estimate the annual exposure of the skin of workers preparing the radiopharmaceuticals, it was assumed that every worker prepares annually about 800 syringes with the average activity of $330 \mathrm{MBq}$ per syringe, while the worker applying radiopharmaceuticals performs annually about 1200 of these procedures with the average activity for one application of $320 \mathrm{MBq}$. For each study group (preparation, application), the correction factors (the ratio of the maximum dose measured in the mapping illustrated in Figure 1 and the result obtained from the finger dosimeter) were also calculated in places where the finger dosimeters are usually worn (the root of the index finger, middle finger and ring finger).

\section{Results}

The results of this study have shown a wide range of measured values of $\mathrm{H}_{\mathrm{p}}(0.07)$. Table 1 summarizes the average value of $\mathrm{H}_{\mathrm{p}}(0.07)$ along with their standard deviations for workers preparing and applying selected radiopharmaceuticals at the PET/CT department. A total of 30 measurements were performed in 10 workers preparing radiopharmaceuticals and 16 measurements for 5 workers applying radiopharmaceuticals (one of these workers was monitored four times in this study).

From the results in Table 1, it can be seen that there are differences in local exposure of extremities of workers engaged in

Tab. 1. Results of the monitoring of workers at a selected PET department in the Czech Republic.

\begin{tabular}{lcc}
\hline Operation & $\begin{array}{c}\text { Number of workers } \\
\text { (number of measurements } \\
\text { accomplished) }\end{array}$ & $\begin{array}{c}\text { Average } \mathrm{H}_{\mathrm{p}}(0,07) \\
\text { normalized to the } \\
\text { activity of } 1 \mathrm{GBq}\end{array}$ \\
\hline Preparation & $10(30)$ & $0.51 \pm 0.37$ \\
Application & $5(16)^{*}$ & $0.80 \pm 0.23 * *$ \\
\hline
\end{tabular}

* Four measurements of one worker

** Two workers have not been considered due to non-standard working procedures

Tab. 2. Correction factors for workers at a PET department in the Czech Republic.

\begin{tabular}{lcccc}
\hline \multirow{2}{*}{ Place and position } & \multicolumn{4}{c}{ Operation } \\
\cline { 2 - 5 } & \multicolumn{2}{c}{ Preparation } & \multicolumn{2}{c}{ Application* } \\
\hline Hand & Left & Right & Left & Right \\
Index finger root & 7 & $5(1)^{* *}$ & 4 & $5(1)^{* *}$ \\
Middle finger root & $7(2)^{* *}$ & $7(3)^{* *}$ & 7 & 9 \\
Ring finger root & $8(2)^{* *}$ & $8(2)^{* *}$ & $9(1)^{* *}$ & $13(1)^{* *}$ \\
\hline
\end{tabular}

* Two workers have not been considered because of non-standard procedures they used. ** The number of workers who were wearing the finger dosimeter in the position indicated.
Tab. 3. Estimate of annual $H_{p}(0.07)$ related to the skin of hands.

\begin{tabular}{lcc}
\hline $\mathrm{H}_{\mathrm{p}}(0,07)$ & \multicolumn{2}{c}{ Operation } \\
\cline { 2 - 3 } & Preparation & Application \\
\hline$<150 \mathrm{mSv}$ & 4 & 0 \\
$150-500 \mathrm{mSv}$ & 6 & 3 \\
$>500 \mathrm{mSv}$ & 0 & $2^{*}$ \\
\hline
\end{tabular}

* Two workers have not been considered because of non-standard procedures applied (they would most probably exceed the relevant dose limit)

the same procedures. The most frequent position, where the local exposure maximum was found, was the position on the tip of the index finger on the palm side of the hand (approximately $50 \%$ of cases during the preparations and in all cases related to the applications). Other positions observed to yield local maximum were observed in workers preparing radiopharmaceuticals: on the palm side of the hand ( $20 \%$ of cases), tip of the middle finger on the palm side of the hand (10\% of cases), tip of the ring finger on the palm side of the hand (10\% cases), and second phalanx of the index finger on the palm side of the hand (10\% of cases).

Finger dosimeters are routinely worn at the root of the index, middle or ring finger. For this reason, it would be appropriate to consider some standardization with respect to the finger dosimeter placement and use of the correction factor (it can vary not only for individual sites, but also for individual professional groups of workers) Indeed, this has been recommended in the conclusion of the project ORAMED (1) where the correction factor of 6 was proposed. The correction factors for individual professional groups are shown in Table 2.

The values of the maximum local exposure were also used to estimate the cases in which the investigation level or dose limit of the skin might be exceeded. These results are summarized in Table 3 .

\section{Discussion}

As far as the preparation of radiopharmaceuticals is concerned, it can be noted that only half of the workers used working tools recommended by the manufacturer, while in 3 of them (experience of these workers was less than 2 years) the exposure of the skin of hands was estimated to be less than $150 \mathrm{mSv} /$ year. In contrast, the six workers who were most likely to exceed the investigative levels, were known to follow "a deeply rooted workflow" reducing their vigilance in working with open sources and possibly resulting in some contamination of hands.

For some workers involved in the applications, it would be appropriate to adopt relevant steps in order to reduce exposure of their hands. In fact, out of five physicians, it was estimated that three of them could exceed the reference level and two physicians may exceed even the relevant annual dose limit (500 mSv).

One of these workers, who was not considered in the study, did not use the recommended method of shielding during the application when he did not use a cannula. His exposure was several times higher than the exposure of other workers engaged in similar applications. 
413-417

This study also confirmed the conclusions of the ORAMED report that the exposure of the skin of the hands of staff members depends significantly on the shielding used. The other person, who was not considered in this study, was also a worker carrying out the application. He was monitored in 11 positions similar to other workers at the same workplace, but the exposure found in a position at the tip of his index finger on the palm side of the hand was much higher. This could be explained by his specific approach in handling radiopharmaceuticals and possibly also by the presence of undetected contamination.

The positive impact of using a semi-automatic dispenser or the application station has been reported also by other authors who claimed that these arrangements can reduce the exposure of extremities up to about 40-90\% (11-14).

On the other hand, it is also worth noting that the use of semiautomatic dispensers or application stations can be rather costly. The department monitored in this study possessed a semi-automatic dispenser station, but the application was performed manually.

An alternative study (15) engaged in the monitoring of exposure of the hands of workers during the application at another PET center in the Czech Republic showed a lower exposure. The work there was carried out by PET radiopharmaceuticals exclusively with tungsten syringe shields and using the cannula. At this department there was no worker exceeding the annual investigative level $(150 \mathrm{mSv})$. Therefore, it seems that radiopharmaceutical applications using the cannula is a more appropriate approach leading to a lower exposure of the hands during the operation, since during the application the worker does not need to "search for a vein", which may be difficult in some patients.

For this reason, it would be appropriate to organize regular training sessions and exercises of workers aimed at the adoption of good hygiene (the use of rubber gloves) and regular inspection of the working area on possible radioactive contamination including the contamination of gloves and hands after any termination of handling radiopharmaceuticals. The regular inspection of contamination of workers is time-consuming and therefore often neglected. Often it is a situation where the workplace is equipped with a series of shielding protective equipment and tools (which are not always routinely used) and technological devices, which are expected to reduce the exposure of workers' hands while handling the radiopharmaceutical (semi-automatic dispensing and application stations). However, workers may be contaminated by accidental spillage of a radiopharmaceutical or touching a contaminated surface including a surface of the contaminated protective equipment or tools). In such cases, localized contamination spots (usually on fingertips (16)) may occur. This may contribute to unnecessary high exposure. For this reason, it is important to prevent contamination (by the use of rubber gloves) and its early detection and subsequent decontamination of hands. Full decontamination of hands is rather difficult because of the possible subcutaneous absorption (17).

As mentioned above, the maximum exposure in most cases occurs on the tips of the fingers, where obviously finger dosimeters are not routinely worn. This usually leads to exposure becoming underestimated. The only method of how to check the compliance with relevant regulatory requirements would be to use appropriate correction factors to assess realistically the maximum exposure. So far, however, this has not been introduced in the Czech Republic. From the results of this work it can be seen that the correction factors vary not only between individual groups (preparation, applications), but they also depend on the hand (right, left). This is why it is appropriate to consider the use of correction factors taking into account also these circumstances.

Taking into account the aforementioned recommendations proposed by ORAMED, it can be concluded that both, the monitoring based on the use of finger dosimeters, and the equipage of nuclear medicine department were in line with the current requirements for this type of workplace. While the correction factors recommended in the ORAMED study was 6 , our measurements showed that these factors should be lower. Apparently, this was mainly due to the use of the semi-automatic dispensing station for the preparation of radiopharmaceuticals. In any case, however, it would be desirable to pay adequate attention to adopt the best practice in all operations and maintain regular training sessions for instructing the workers how to further reduce their exposure. Attention should also be concentrated on the elimination of potential radioactive contamination of hands.

\section{Conclusion}

It is important to raise awareness among workers at the PET departments regarding radiation protection because, as it has been demonstrated by the monitoring results discussed above, the exposure of workers' hands depends largely on their personal approach in performing relevant operations. The use of adequate shielding and tools lengthening the distance between the source and the tips of the fingers presents one of the methods. Other suitable means of reducing the exposure of the hands includes also the application of semi-automatic dispensing stations or applicators of radiopharmaceuticals which shorten the time of worker's contact with an open source. Proper execution of the work action, as well as subsequent control of the contamination may also contribute to minimizing the radiation exposure.

An essential step to proper quantification of the skin exposure of the hand finger includes wearing the TLDs during all operations with radiopharmaceuticals. Based on the unified location of the finger dosimeter not only within one nuclear medicine department but at all departments, it would then be possible to compare workers' exposure and thus introduce an appropriate correction factor for converting the reading of routinely used personal dosimeter, assessing the maximum exposure and consequently comparing it to the relevant dose limit. In case of the absence of unified approach in positioning the finger dosimeters, it would be necessary to calculate and apply other relevant correction factors taking into account the relation between the maximum exposure and TLD reading.

\section{References}

1. European Radiation Dosimetry E.V. Optimization of Radiation Protection of Medical Staff: Extremity Dosimetry in Nuclear Medicine. EURODAS Report 2012-2. Braunschweig 2012; 133-177. 
2. Belgian Nuclear Research Centre: Optimization of Radiation Protection of Medical Staff. (online). 2014 (Accessed 2015-05-02). Available on: http://www.oramed-fp7.eu/

3. Kemerink GJ, Vanhavere F, Barth I. Extremity Dose of Nuclear Medicine Personnel: A Concern. Eur J Med Mol Imaging 2012; 39: 529-532.

4. Vanhavere F, Carinou E, Donadille, L, Ginjaume, M, Jankowski, J, Rimpler, J, Merce, S. M. An Overview on Extremity in Medical Applications. Radiation Protection Dosimetry 2008; 129 (1 - 3): 350-355.

5. Struelens L et al. Extremity Doses of Medical Staff for Complex Interventional Procedures and in Nuclear Medicine ExDos: Extremity Dosimetry in Nuclear Medicine. Final Report 2010. Mol 2010; 31 - 62.

6. Donadille L, Carinou E, Ginjaume M, Jankowski J, Rimpler A, Merce MS, Vanhaver F. An Overview of the Use of Extremity Dosemeters in some European Countries for Medical Applications. Radiation Protection Dosimetry 2008; 131 (1): $62-66$.

7. Carnicer A, Sance Merce M, Baechler S, Barth I, Donadille N, Ferrari P, Fülöp M, Ginjaume M, Gualdrini G, Krim S, Mariotti F, Ortega X, Rimpler A, Ruiz N, Vanhavere F. Hand Exposure in Diagnostic Nuclear Medicine with ${ }^{18} \mathrm{~F}$ - and ${ }^{99 \mathrm{~m}} \mathrm{Tc}$-labelled Radiopharmaceuticals - Results of the ORAMED Project. Radiation Measur 2011; 46: 1277-1282.

8. Sance Merce M, Ruiz N, Barth I, Carnicer A, Donadille N, Ferrari P, Fulop M, Ginjaume M, Gualdrini G, Krim S, Mariotti F, Ortega X, Rimpler A, Vanhavere F, Baechler S. Extremity Exposure in Nuclear Medicine: Preliminary Results of the European Study. Radiation Protection Dosimetry 2011; 144: 515-520.

9. Sans-Merce $\mathbf{M}$ et al. Recommendations to Reduce Hand Exposure for Standard Nuclear Medicine Procedures. Radiation Measur 2011; 46: $1330-1333$.
10. Carnicer A, Ginjaume M, Duch MA, Vanhavere F, Sanc-Merce M, Baechler S, Barth I, Donadille N, Ferrari P, Fulop M, Gualdrini G, Krim S, Mariotti F, Ortega X, Rimpler A, Ruiz N, Olko, P. The use of Different Types of Thermoluminiscent Dosimeters to Measure Extremity Doses in Nuclear Medicine. Radiation Measur 2011; 46: 1835-1838.

11. Lecchi $\mathbf{M}$ et al. Validation of a New Protocol for ${ }^{18} \mathrm{~F}-\mathrm{FDG}$ Infusion Using an Automatic Combined Dispenser and Injector System. Eur J Nucl Med Mol Imag 2012; 39: 1720 - 1729.

12. Antic V et al. Radiation Exposure to Nuclear Medicine Staff Involved in PET/CT Practice in Serbia. Radiation Protection Dosimetry 2014; 162 (4): $577-58$

13. Doherty OJ et al. Validation of an Automated Dose-dispensing System for ${ }^{18} \mathrm{~F}$-FDG Administrations and Associated Reduction in Operator Extremity Dose. Nucl Med Commun 2014; 35 (2): 151 - 159.

14. Covens P, Berus D, Vanhavere F, Caveliers V. The Introduction of Automated Dispensing and Injection during PET Procedures: A Step in the Optimization of Extremity Doses and Whole-body Doses of Nuclear Medicine Staff. Radiation Protection Dosimetry 2010; 140 (3): 205 - 258.

15. Hudzietzová $\mathbf{J}$ et al. Radiační zátěž rukou pracovníků během přípravy a aplikace radiofarmak značených radionuclidem ${ }^{18} \mathrm{~F}$. Čes Radiol 2014; 68 (4): $318-322$.

16. Covens $\mathbf{P}$ et al. The Contribution of Skin Contamination Dose to the Total Extremity Dose of Nuclear Medicine Staff: First Results of an Intensive Survey. Radiation Measur 2011; 46: 1291 - 1294.

17. Covens P et al. Skin Dose Rate Conversion Factors after Contamination with Radiopharmaceuticals: Influence of Contamination Area, Epidermal Thickness and Percutaneous Absorption. J Radiol Prot 2013; 33: 381 - 393.

Received May 23, 2015. Accepted November 29, 2015. 